\section{The clinical and subclinical features of spinal cord injury on magnetic resonance imaging of patients with $\mathrm{N}_{2} \mathrm{O}$ intoxication}

\author{
Tran Anh Tuan,1 Nguyen Minh Duc,,3 \\ Than Van Sy, ${ }^{4}$ Trinh Minh Hung, 5 \\ Tran Cuong,5 Nguyen Quang Anh,1,5 \\ Vu Dang Luu,1,5 Pham Minh Thong1,5 \\ 1Department of Radiology, Bach Mai \\ Hospital, Hanoi; 2Department of \\ Radiology, Pham Ngoc Thach University \\ of Medicine, Ho Chi Minh City; \\ 3Department of Radiology, Children's \\ Hospital 2, Ho Chi Minh City; \\ ${ }_{4}^{4}$ Department of Radiology, Viet Duc \\ Hospital, Hanoi; 5Department of \\ Radiology, Hanoi Medical University, \\ Ha Noi, Vietnam
}

\begin{abstract}
Nitrous oxide $\left(\mathrm{N}_{2} \mathrm{O}\right)$ is a weak anesthetic gas that was first used in 1844 in the field of dental anesthesia. However, currently, $\mathrm{N}_{2} \mathrm{O}$ is being abused for entertainment purposes in the form of $\mathrm{N}_{2} \mathrm{O}$-filled balloons, called funky balls, which can cause many adverse effects, especially nervous system injury. This study aimed to investigate the detailed clinical and subclinical features associated with $\mathrm{N}_{2} \mathrm{O}$ intoxication. We retrospectively reviewed 47 patients diagnosed with $\mathrm{N}_{2} \mathrm{O}$ intoxication, from May 2018 to July 2019, and collected demographic data, clinical and laboratory tests, and spinal cord magnetic resonance imaging (MRI) findings. The mean time of funky ball use was 8.8 months, with a mean use of 36.3 balls per day. All patients presented with superficial sensory disorders. Reductions in muscle strength, decreased vibration sensation, and decreased or lost tendon reflexes were the most common clinical signs of $\mathrm{N}_{2} \mathrm{O}$ intoxication. Romberg sign and Lhermitte sign were observed in 39 patients $(83 \%)$ and 21 patients $(44.7 \%)$, respectively. Spinal cord lesions on MRI were observed in 32 patients $(68.1 \%)$, which mostly presented with an inverted $\mathrm{V}$ sign. The total duration of $\mathrm{N}_{2} \mathrm{O}$ use, the number of days of using $\mathrm{N}_{2} \mathrm{O}$ per week, and the presence of Lhermitte sign $(\mathrm{P}<0.05)$ were significantly different between patients with and without spinal cord lesions on MRI. Serum levels of homocysteine and vitamin B12 were significantly different between the time of admission and discharge $(\mathrm{P}<0.05)$. Our study
\end{abstract}

indicated that the days of using $\mathrm{N}_{2} \mathrm{O}$ per week was significantly associated with Spinal Cord Injuries (SCI) on MRI. According to the Receiver Operating Characteristic (ROC) curve analysis, a cutoff days of using per week value of 2.5 days could predict SCI with a sensitivity of $81.3 \%$, a specificity of $73.3 \%$, and an area under the ROC curve (AUC) of 0.813 . Changes in the serum levels of homocysteine and vitamin B12 were effective markers for the evaluation of treatment response.

\section{Introduction}

Nitrous oxide $\left(\mathrm{N}_{2} \mathrm{O}\right)$ has been used in surgery and dentistry for over 150 years, as an inhaled anesthetic. ${ }^{1}$ Recently, $\mathrm{N}_{2} \mathrm{O}$ has been used in filled balloons, known as funky balls, which can be used legally in bars and night clubs, due to its euphoric effects. A study in 2014 found that $\mathrm{N}_{2} \mathrm{O}$ was commonly used at festivals and night clubs in the form of funky balls, especially in the United Kingdom and the United States. ${ }^{2}$

The overuse of $\mathrm{N}_{2} \mathrm{O}$, however, can lead to intoxication, which can affect the nervous system with some sequelae if diagnosis and treatment are delayed.3-5 The spinal cord is a relatively specific injury site associated with $\mathrm{N}_{2} \mathrm{O}$ poisoning that has been identified in several studies, in which researchers evaluated the relationships between $\mathrm{N}_{2} \mathrm{O}$ exposure time, dosage, and clinical severity. However, these studies have primarily been case reports or studies with small sample sizes. ${ }^{3-6}$ Additionally, these reports have not provided detailed correlations among the lesions identified on magnetic resonance imaging (MRI), clinical symptoms, and serological tests.

Thus, we performed this study to assess the clinical and paraclinical examinations necessary for the diagnosis of $\mathrm{N}_{2} \mathrm{O}$ intoxication, and to identify which factors could be related to imaginal lesions of the spinal cord.

\section{Materials and Methods}

\section{Patient population}

This retrospective study was performed at the Poison Control Center, Bach Mai Hospital, Hanoi, Vietnam, from May 2018 to July 2019. Ethical clearance was given by the institute's ethics committee.

\section{Clinical parameters}

All patients with a history of using one
Correspondence: Nguyen Minh Duc, Department of Radiology, Pham Ngoc Thach University of Medicine, Ho Chi Minh City, Vietnam.

E-mail: bsnguyenminhduc@pnt.edu.vn

Key words: $\mathrm{N}_{2} \mathrm{O}$, Intoxication, Vitamin B12, Homocysteine, Spinal cord, Nitrous oxide

Contributions: NMD and TAT contributed equally to this article therefore considered as co-first authors. NMD and TAT gave a substantial contribution in acquisition, analysis, and data interpretation. NMD, TVS, TC, TMH prepared, drafted, and revised manuscript critically for important intellectual content. Each author gave the final approval of the version to be published and agreed to be accountable for all aspects of the work, ensuring that questions related to the accuracy or integrity of any part of the work are appropriately investigated and resolved.

Conflict of interest: The authors declare no conflict of interest.

Funding: None.

Ethical approval and informed consent: Institutional review board of Bach Mai hospital approved this study. Informed consent of patients was obtained.

Received for publication: 5 June 2020 .

Revision received: 14 June 2020.

Accepted for publication: 15 June 2020.

This work is licensed under a Creative Commons Attribution NonCommercial 4.0 License (CC BY-NC 4.0).

(C) Copyright: the Author(s), 2019

Licensee PAGEPress, Italy

Neurology International 2020; 12:8652

doi:10.4081/ni.2020.8652

or more inhaled doses of $\mathrm{N}_{2} \mathrm{O}$ were included in this study, following the first-onset occurrence of paresthesia and symmetrical distal limb weakness, and information was collected regarding the duration of $\mathrm{N}_{2} \mathrm{O}$ use, the days of use per week, and the number of balls used per day. Myelopathy was identified by clinical examinations, presenting as a superficial sensory disorder, decreased vibration sensation, decreased muscle strength, the appearance of Romberg's sign (the patient was unable to maintain a standing position for 60 seconds, with the feet pinched and eyes closed), ${ }^{7}$ Lhermitte's sign (the patient reported a pain similar to an electric shock spreading along the spine to the extremities when asked to bend his or her neck), ${ }^{8}$ and abnormal tendon reflexes. 


\section{Subclinical parameters}

A laboratory panel for polyneuropathy examinations, including red blood cells (RBCs, normal levels: 4.2-6.1 × $10^{6}$ cells), serum vitamin B12 level (normal range: 150-946 pg/mL), serum hemoglobin level (HGB, normal range: $12-17.5 \mathrm{~g} / \mathrm{dL}$ ), and serum homocysteine level (normal range: 4-15 $\mu \mathrm{mol} / \mathrm{L}){ }^{9}$ were indicated for all patients at the time of admission and the end of the treatment period. MRI of the brain and cervical and thoracic spine was performed at the time of admission, and all abnormal features were recorded. All patients were scanned with a 1.5 Tesla MRI (Ingenia, Philips, Best, The Netherlands). Brain MRI included axial T2-weighted imaging (T2W), coronal fluid-attenuated inversion recovery (FLAIR), axial T1weighted imaging (T1W), axial diffusionweighted imaging (DWI), and axial 3dimensional $\mathrm{T} 1 \mathrm{~W}$, with contrast enhancement (CE). Cervical and thoracic MRI included sagittal $\mathrm{T} 1 \mathrm{~W}$, sagittal $\mathrm{T} 2 \mathrm{~W}$, and axial T1W with $\mathrm{CE}$.

\section{Statistical analysis}

IBM SPSS Statistics v. 20 (IBM corp., New York, USA) was used to analyze the data. Continuous variables are presented as the mean standard deviation Differences between the levels of RBC, HGB, vitamin $\mathrm{B} 12$, and homocysteine, at the time of admission and the end of the treatment period, were analyzed by the Wilcoxon test. The Mann-Whitney U test, Fisher's exact test, or the Chi-squared test were used for comparisons of clinical and paraclinical characteristics between patients with and without spinal cord lesions. Multivariate logistic regression was used to reveal significant parameters. Receiver Operating Characteristic (ROC) curve analysis and the Youden index were used to choose the best cut-off point for significant factors. A P value $<0.05$ was considered significant.

\section{Results}

As described in Table 1, our study included 47 patients with $\mathrm{N}_{2} \mathrm{O}$ intoxication, who were admitted to Bach Mai Hospital, from May 2018 to July 2019. The average treatment time was $8.0 \pm 1.5$ days, and all patients recovered effectively. All patients presented superficial sensory disorders. Reductions in muscle strength, decreased vibration sensations, and decreased or lost tendon reflexes were the most common clinical signs. Romberg sign and Lhermitte sign were observed in 39 patients $(83 \%)$ and 21 patients $(44.7 \%)$, respectively.
Comparisons of test index values between the time of admission and discharge are shown in Table 2. Decreased hemoglobin level was found in 15 patients (32\%) at the time of admission, and 27 patients $(57.4 \%)$ displayed decreased vitamin B12 levels $(<150 \mathrm{pmol} / \mathrm{mL})$ at the time of admission. All patients had normal or increased vitamin B12 levels at the time of discharge. A total of 41 patients $(87 \%)$ had
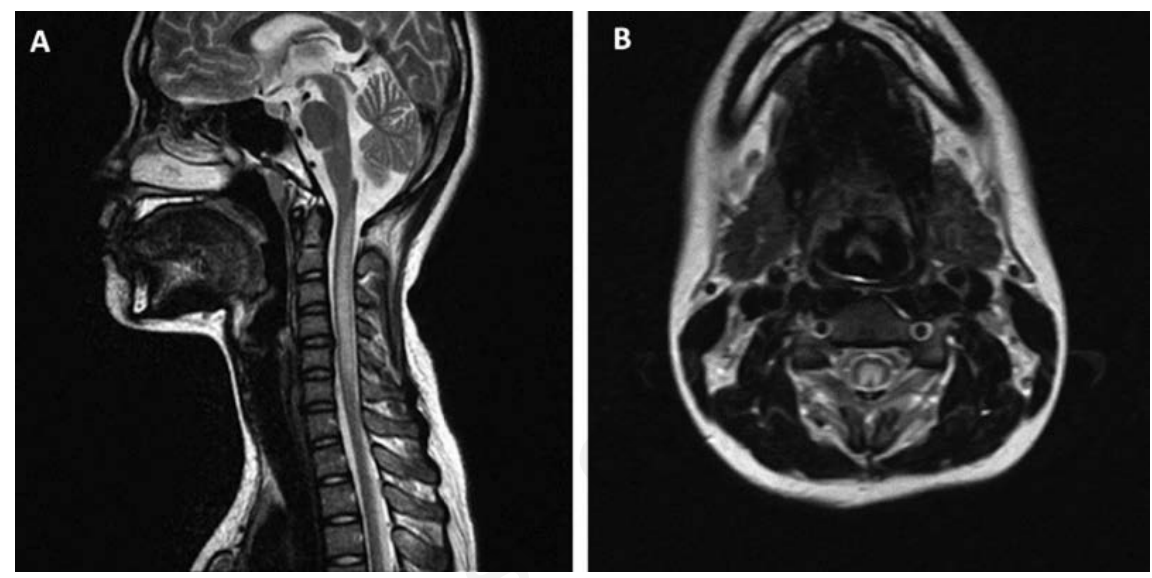

Figure 1. A 17-year-old female patient, with a history of using $\mathrm{N}_{2} \mathrm{O}$ for a long time. (A) Spinal cord injury appeared as hyperintense on the sagittal T2W image, from $\mathrm{C} 1$ to $\mathrm{CG}$. (B) Axial T2W image, with hyperintense lesion located in the posterior column, with bilateral symmetry, appearing as an "inverted V" sign.

\section{Table 1. Patient demographics.}

\begin{tabular}{lcc}
\hline Feature & Mean \pm SD / N (\%) & Range \\
Age (years) & $24.4 \pm 6.2$ & $15-50$ \\
Gender (male/female) & $23 / 24$ & \\
\hline Duration of using $\mathrm{N}_{2} \mathrm{O}$ (months) & $8.8 \pm 7.1$ & $2-36$ \\
Days of using $\mathrm{N}_{2} \mathrm{O}$ per week & $3.2 \pm 1.3$ & $1-6$ \\
\hline Balls per day (ball) & $36.3 \pm 23.3$ & $10-100$ \\
Last $\mathrm{N}_{2} \mathrm{O}$ exposure to symptom onset (days) & $8.7 \pm 6.8$ & $1-35$ \\
\hline Superficial sensory disorder & $47(100 \%)$ & \\
Decreased sensation of vibration & $35(74.5 \%)$ & \\
\hline Decreased muscle strength & $41(87.2 \%)$ & \\
Decreased/loss tendon reflexes & $40(85.1 \%)$ & \\
\hline Romberg's sign & $39(83 \%)$ & \\
Lhermitte's sign & $21(44.7 \%)$ & \\
\hline
\end{tabular}

Table 2. Comparison of test index values between admission and discharge.

\begin{tabular}{|c|c|c|c|}
\hline Index & Admission $(n=47)$ & Discharge $(n=47)$ & P-value \\
\hline $\begin{array}{l}\mathrm{RBC}(\operatorname{mean} \pm \mathrm{SD}) \\
(\min -\max )(\mathrm{T} / \mathrm{L})\end{array}$ & $\begin{array}{l}4.28 \pm 0.64 \\
(3.19-5.75)\end{array}$ & $\begin{array}{l}4.34 \pm 0.63 \\
(3.21-6.04)\end{array}$ & $0.030 * \mathrm{a}$ \\
\hline $\begin{array}{l}\text { HGB }(\text { mean } \pm \text { SD) } \\
(\min -\max )(g / L)\end{array}$ & $\begin{array}{l}130.17 \pm 17.04 \\
(87-162)\end{array}$ & $\begin{array}{l}130.40 \pm 15.20 \\
(89-163)\end{array}$ & $0.651 \mathrm{a}$ \\
\hline $\begin{array}{l}\text { Homocysteine }(\text { mean } \pm S D) \\
(\min -\max )(\mu \mathrm{mol} / \mathrm{L})\end{array}$ & $\begin{array}{l}49.73 \pm 27.65 \\
(5.1-129)\end{array}$ & $\begin{array}{c}10.93 \pm 2.42 \\
(4.8-15.7)\end{array}$ & $<0.001^{* a}$ \\
\hline $\begin{array}{l}\text { Vitamin B12 }(\text { mean } \pm \text { SD }) \\
(\min -\max )(\mathrm{pmol} / \mathrm{mL})\end{array}$ & $\begin{array}{l}365.62 \pm 437.28 \\
\quad(62-1476)\end{array}$ & $\begin{array}{c}1362.17 \pm 179.73 \\
(728-1491)\end{array}$ & $<0.001^{*_{a}}$ \\
\hline
\end{tabular}

aP-value was calculated using the Wilcoxon test.* Indicates a significant statistical difference as $\mathrm{P}<0.05$. RBC, red blood cells; HGB, hemoglobin; SD, Standard deviation. increased homocysteine levels at the time of patient $(2.1 \%)$ continued to show a slight increase in homocysteine levels at the time

MRI, whereas spinal cord lesions were observed in 32 patients $(68.1 \%)$. Clinical and imaging characteristics of SCI on MRI are presented in Table 3. Among those with 西 
SCI, 29 patients had cervical spinal lesions alone, whereas thoracic spinal lesions were found in 2 patients, and 1 patient had lesions in both the cervical and thoracic spinal regions. In the SCI groups, most patients had hyperintense lesions on the T2W image, along with an inverted $V$ sign (Figure 1). The average number of injured segments was $3.4 \pm 2.8(0-12)$. Neither spinal cord hypertrophy nor post-contrast enhancement lesions were observed.

As shown in Table 4, multivariate logistic regression revealed that only days of using per week significantly affected the MRI appearance of spinal cord lesions. According to the ROC analysis, a cut-off days of using per week value of 2.5 days relative to SCI yielded a sensitivity of $81.3 \%$, a specificity of $73.3 \%$, and an area under the curve (AUC) of 0.813 (Figure 2). been reported by other authors, such as Patel et al. 12 and Li et al.13, who reported rates of $67 \%$ and $64 \%$, respectively. Decreased or lost tendon reflexes were also common symptoms in our study, which was similar to the report by Li et al. ${ }^{13}$ Our results were comparable with those reported by previous studies, which indicated that Romberg's sign was also a very common symptom. 11,14,15 Lhermitte's sign was found in 21 patients in our study $(44.7 \%)$, which was higher than the occurrences reported in the studies by Oussalah et al. 14 (15\%) and Wang et al. ${ }^{11}(30 \%)$.

Vitamin B12 (cobalamin) is a cofactor of methionine synthase, which converts homocysteine and 5 methyltetrahydrofolates into methionine and tetrahydrofolate (Figure 3). Methionine plays an important role in the synthesis of the myelin sheath around nerve axons, whereas tetrahydrofolate is necessary for DNA synthesis. ${ }^{16} \mathrm{~N}_{2} \mathrm{O}$ oxidizes the cobalt nucleus of vitamin $\mathrm{B} 12$, from the $1+$ valence to the $3+$ valence state, which turns inactivates methylcobalt, causing the loss of function as a cofactor for methionine synthase, inhibiting the conversion of homocysteine into methionine. As a result of this phenomenon, the serum methionine level decreases, and the serum homocysteine level increases. The decreased methionine level results in nerve damage to both the central and peripheral nervous systems. ${ }^{17}$ Homocysteine, a sulfurcontaining amino acid, does not appear to have any functional role in the body, except as part of the methionine metabolism pathway. However, increasing homocysteine levels may cause many adverse effects, especially associated with cardiovascular

\section{Discussion}

Uncontrolled, prolonged, or overuse of $\mathrm{N}_{2} \mathrm{O}$ for entertainment purposes may cause many undesirable effects, especially nervous system injuries. Most of the patients in our study were young people, under 30 years old. The most commonly presented clinical symptoms included superficial sensory disorders and limb weakness, which are similar to those reported in other studies. 10,11

The posterior column of the spinal cord, which plays a crucial role in deep sensory conduction, including the sensory perception of position and vibration, is the most common injury location associated with $\mathrm{N}_{2} \mathrm{O}$ intoxication.5,6,10 In our study, the reduced sensation of vibration was identified in $74.5 \%$ of patients. Lower rates have

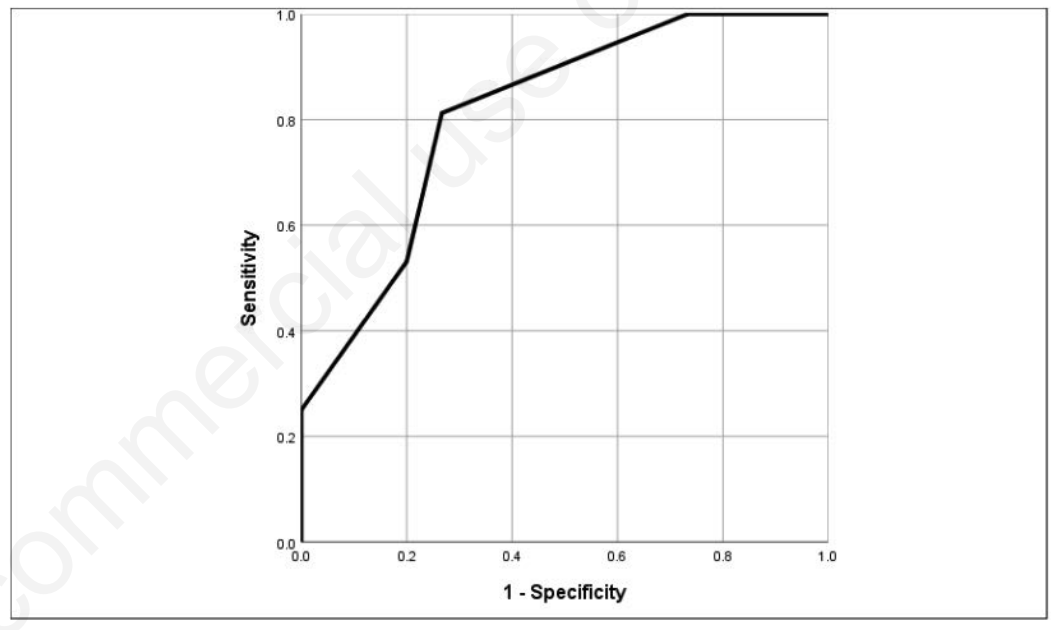

Figure 2. ROC curve of "days of using per week".

Table 3. Clinical and subclinical feature comparison between patients with and without spinal cord lesions.

\begin{tabular}{|c|c|c|c|}
\hline Features & $\begin{array}{l}\text { Patients with spinal cord } \\
\text { lesion }(\mathrm{n}=32)\end{array}$ & $\begin{array}{l}\text { Patients without spinal cord } \\
\text { lesion }(\mathrm{n}=15)\end{array}$ & P-value \\
\hline Duration of using (mean \pm SD) (min-max) (months) & $13.0 \pm 9.3(2-36)$ & $6.8 \pm 4.8(2-24)$ & $0.01 * b$ \\
\hline Days of using per week (mean \pm SD) (min-max) (days) & $3.6 \pm 2.2(2-6)$ & $2.2 \pm 1.1(1-4)$ & $<0.001^{* b}$ \\
\hline Balls per day (mean \pm SD) (min-max) (balls) & $40.0 \pm 25.5(10-100)$ & $28.3 \pm 15.5(10-60)$ & $0.188 \mathrm{~b}$ \\
\hline RBC\# (mean \pm SD) $(\min -\max )(T / L)$ & $4.2 \pm 0.6(3.19-5.72)$ & $4.7 \pm 0.7(3.36-5.75)$ & $0.226^{b}$ \\
\hline HGB\# (mean \pm SD) (min-max) (g/L) & $126.6 \pm 16.4(87-158)$ & $137.7 \pm 16.3(108-162)$ & $0.031^{* b}$ \\
\hline Homocysteine\# (mean \pm SD) $(\min -\max )(\mu \mathrm{mol} / \mathrm{L})$ & $46.8 \pm 25.4(5.1-83)$ & $56.0 \pm 32.0(5.89-129)$ & $0.332^{b}$ \\
\hline Vitamin B12\# (mean \pm SD) (min-max) (pmol/mL) & $383.12 \pm 424.4(65-1476)$ & $328.27 \pm 476.7(62-1476)$ & $0.451^{\mathrm{b}}$ \\
\hline Lhermitte sign & $20(62.5 \%)$ & $1(6.7 \%)$ & $<0.001 *_{c}$ \\
\hline Romberg sign & $29(90.6 \%)$ & $10(66.7 \%)$ & $0.089 \mathrm{c}$ \\
\hline Hyperintense on T2W & $32(100 \%)$ & 0 & $<0.001^{*} \mathrm{c}$ \\
\hline Hypointense on T1W & 10 & 0 & $<0.001^{*} \mathrm{c}$ \\
\hline "Inverted V" sign & $30(94 \%)$ & 0 & $<0.001^{*} \mathrm{c}$ \\
\hline
\end{tabular}

\#Values at hospital admission. bP-value was calculated using the Mann-Whitney U test. cP-value was calculated using Fisher's exact/chi-squared test. *Indicates a significant statistical difference as $\mathrm{P}<0.05$. RBC, red blood cells; HGB, hemoglobin; T1W, T1-weighted; T2W, T2-weighted; SD, Standard deviation 
problems, such as increased coagulation, altered endothelial adhesion, and atherosclerosis. ${ }^{18}$

Serum vitamin B12 levels are important to evaluate in patients with $\mathrm{N}_{2} \mathrm{O}$ intoxication. Our results, however, were comparable to those presented in previous studies, which confirmed that the decreased vitamin B12 levels $(<150 \mathrm{pmol} / \mathrm{mL})$ are a common outcome, but has a lower sensitivity rate than the increased homocysteine concentration, which may represent a useful biomarker for $\mathrm{N}_{2} \mathrm{O}$ intoxication. ${ }^{13,14,19}$ When comparing the values of a series of test parameters between the time of admission and discharge, we found that the serum levels of homocysteine and vitamin B12 in patients were significantly different between these two time points $(\mathrm{P}<0.001)$.

Our study found that days of using per week was a significant factor associated with the development of spinal cord lesions. In the ROC analysis, a cut-off days of using per week value of 2.5 days predicted SCI occurrence with a sensitivity of $81.3 \%$, a specificity of $73.3 \%$, and an AUC of 0.813 . The overuse of $\mathrm{N}_{2} \mathrm{O}$ causes the inactivation of vitamin $\mathrm{B} 12$, leading to the functional deficiency of vitamin B12, which causes subacute, degenerative spinal cord disease, with major lesions on the cervical spine and the upper part of the thoracic spine. For severe cases, lesions may prolong both the cervical and thoracic spine. ${ }^{10,14}$ Similar to the results of previous studies, we did not identify any brain parenchymal injuries on MRI.1,11,13,14 All detectable lesions were hyperintense on $\mathrm{T} 2 \mathrm{~W}$ and were located in the posterior column. Neither post-contrast enhancement nor spinal hypertrophy was observed. Moreover, the inverted $V$ sign was the most common finding on MRI. This sign is caused by the subacute, symmetrical, combined degeneration of the dorsal columns of the cervicothoracic spinal cord and may be a specific finding associated with vitamin B12 deficiency. 20 There are some limitations to this study. First, this study was has a retrospective design. Second, this study used a small sample. In addition, the biochemical tests performed were not abundant. Finally, we did not investigate injuries in other systems, except for the central nervous system. We recommend that further studies should be performed, with larger sample sizes and multi-hospital participation and that the investigation be expanded to include multiple body systems.

\section{Conclusions}

The overuse of $\mathrm{N}_{2} \mathrm{O}$ has serious consequences, especially damage to the nervous system. Days of using per week was significantly associated with the MRI appearance of spinal cord lesions. The cervical spinal cord is the most common site involved on MRI, with an inverted $V$ appearance. Changes in homocysteine and vitamin B12 levels were valuable for the assessment of treatment response.

\section{References}

1. Garakani A, Jaffe RJ, Savla D, et al. Neurologic, psychiatric, and other medical manifestations of nitrous oxide abuse: A systematic review of the case literature. Am J Addict 2016;25:35869.

2. Kaar SJ, Ferris J, Waldron J, et al. Up: The rise of nitrous oxide abuse. An international survey of contemporary nitrous oxide use. J Psychopharmacol 2016;30:395-401.

3. Emmanouil DE and Quock RM. Advances in Understanding the Actions of Nitrous Oxide. Anesth Prog 2007;54:9-18.

4. Jalbert ER, Fahmi A, Li C, et al. Subacute Combined Degeneration of the Dorsal Columns in A Patient With Nitrous Oxide Induced B12 Inactivation: A Case Report. J Neurol Neurosci 2016;6:3.

5. Ilniczky S, Jelencsik I, Kenez J, Szirmai I. MR findings in subacute combined degeneration of the spinal cord caused by nitrous oxide anaesthesia - two cases. Eur J Neurol 2002;9:101-4.

6. Safari A, Emadi F, Jamali E, BorhaniHaghighi A. Clinical and MRI manifestations of nitrous oxide induced vitamin B12 deficiency: A case report. Iran J Neurol 2013;12:111-3.

7. Singer MA, Lazaridis C, Nations SP, Wolfe GI. Reversible nitrous oxideinduced myeloneuropathy with pernicious anemia: Case report and literature review. Muscle Nerve 2008;37:125-9.

8. Yuan JL, Wang SK, Jiang T, Hu WL. Nitrous oxide induced subacute combined degeneration with longitudinally extensive myelopathy with inverted Vsign on spinal MRI: a case report and literature review. BMC Neurol 2017;17:222.

9. Hathout L, El-Saden S. Nitrous oxideinduced B12 deficiency myelopathy: Perspectives on the clinical biochemistry of vitamin B12. J Neurol Sci lesions and historical features of $\mathrm{N}_{2} \mathrm{O}$ abuse.

\begin{tabular}{lccc} 
Parameters & B & $95 \% \mathrm{CI}$ & P-value \\
Duration of using & 0.062 & $0.936-1.209$ & 0.342 \\
Days of using per week & -0.957 & $0.166-0.886$ & $0.025^{\mathrm{a}}$ \\
\hline Balls per day & -0.018 & $0.943-1.022$ & 0.374 \\
\hline
\end{tabular}

aP value was calculated using Multivariate logistic regression; ${ }^{*} \mathrm{P}<0.05$. CI, Confidence Interval. 
2011;301:1-8.

10. Lan SY, Kuo CY, Chou CC, et al. Recreational nitrous oxide abuse related subacute combined degeneration of the spinal cord in adolescents - A case series and literature review. Brain Dev 2019;41:428-35.

11. Wang YY, Wang RB, Hong W, et al. [Clinical features of long segmental myelopathy cause by nitrous oxide]. Beijing Da Xue Xue Bao Yi Xue Ban 2019;51:288-92.

12. Patel KK, Mejia Munne JC, Gunness VRN, et al. Subacute combined degeneration of the spinal cord following nitrous oxide anesthesia: A systematic review of cases. Clin Neurol Neurosurg 2018;173:163-8.

13. Li HT, Chu CC, Chang KH, et al. Clinical and electrodiagnostic characteristics of nitrous oxide-induced neu- ropathy in Taiwan. Clin Neurophysiol 2016;127:3288-93.

14. Oussalah A, Julien M, Levy J, et al. Global Burden Related to Nitrous Oxide Exposure in Medical and Recreational Settings: A Systematic Review and Individual Patient Data Meta- Analysis. J Clin Med 2019;8:551.

15. Onrust MR, Frequin ST. Subacute Combined Spinal Cord Degeneration by Recreational Laughing Gas $\left(\mathrm{N}_{2} \mathrm{O}\right)$ Use. J Cent Nerv Syst Dis 2019;11: 1179573519838277.

16. Garakani A, Welch AK, Jaffe RJ, et al. Psychosis and Low Cyanocobalamin in a Patient Abusing Nitrous Oxide and Cannabis. Psychosomatics 2014;55: 715-9.

17. Manavifar L, Nemati Karimooy H, Jamali J, et al. Homocysteine, Cobalamin and Folate Status and their
Relations to Neurocognitive and Psychological Markers in Elderly in Northeasten of Iran. Iran J Basic Med Sci 2013;16:772-80.

18. Nappo F, De Rosa N, Marfella R, et al. Impairment of endothelial functions by acute hyperhomocysteinemia and reversal by antioxidant vitamins. JAMA 1999;281:2113-8.

19. Chen HJ, Huang CS. Nitrous Oxideinduced Subacute Combined Degeneration Presenting with Dystonia and Pseudoathetosis: A Case Report. Acta Neurol Taiwan 2016;25:50-5.

20. Narra R, Adinarayana M, Naganarasimharaju J, Pradeep G. "Inverted V sign" in sub-acute combined degeneration of cord. J Clin Diagn Res 2015;9:TJ01. 